\title{
Knowledge, Attitude And Practice Towards Water Supply, Sanitation And Hygiene (Wash) Among Residents In Arsi Nagele Town, South Eastern Ethiopia
}

Getachew Meka Mako ( $\sim$ kaayyoo2005@gmail.com )

Hawassa University College of Medicine and Health Sciences

Yordanos Kinfe Gelanh

Hawassa University

Bucho Yetera Mamo

Hawassa University

Research article

Keywords: Watersupply, sanitation,hygiene, Arsi Nagele

Posted Date: September 12th, 2019

DOl: https://doi.org/10.21203/rs.2.14375/v1

License: (c) (i) This work is licensed under a Creative Commons Attribution 4.0 International License.

Read Full License 


\section{Abstract}

Background The national water coverage has been in increasing trend. However, unsafe water supply and poor sanitation practice was the major health concern which is causing diseases with considerable morbidity and mortality in Ethiopia.

Objective To assess knowledge, attitude and practice of Arsi Nagele town inhabitants on water supply, sanitation and hygiene at household level.

Method Community-based cross sectional study design was used at household level in Arsi Nagele town in April, 2019. Data was collected with structured questionnaires through face to face interview. Data was analyzed using SPSS version 20 statistical software.

Result Four out of ten (43.8\%) respondents know private taps are safe for drinking and domestic use while 116(40.4\%) shared taps are safe. Moreover, 31(10.5\%) know hand pump are safe and $16(5 . .3 \%)$ know unprotected well are safe for any domestic purpose. The majority of the respondents $260(90.5 \%)$ had positive attitude whereas $21(7.1 \%)$ of the respondents negative and $8(2.5 \%)$ neutral attitude to the issue that in proper disposal of solid and liquid waste may contribute to the transmission of disease. While 241 (83.9\%) of the respondent had positive attitude while $32(10.8 \%)$ and $16(5.2 \%)$ of the respondents had negative and neutral attitude to the view that human waste disposal is not a problem in that area.

Conclusion The majority of respondent $250(87.1 \%)$ had good practice in case of cover the water storage container during the time of visit while $39(12.9 \%)$ of the respondent had bad practice. This calls urgent action to creat awareness on health education and hygiene household be promoted to influence the resident's attitude that target personal, household and community hygiene and sanitation.

\section{Background}

Water and sanitation entitles the human right, without discrimination, to physical and affordable access, in all spheres of life, to sanitation which is safe, hygienic, secure, socially and culturally acceptable, and ensures dignity (Telmo, 2002). In Sub-Saharan Africa access to water supply and sanitation has improved, but the region lags behind all other developing regions: access to safe drinking water has increased from $49 \%$ in 1990 to $57 \%$ in 2011 , while in the same time span the access to improved sanitation has only risen from $28 \%$ to $31 \%$ though the government of Ethiopia eagerly working on improving the standard of of WASH service for tracking progress towards the 2030 suatainable development goal target (6.1 and 6.2 and 6.3)(WHO/UNICEF-JMP, 2017).

Lack of water supply, sanitation and hygiene is the major cause of morbidity and mortality(Dreibelbis et al., 2013). It is estimated that 10,000 die every day from a range of water and sanitation related illness. The impact of inadequate water and sanitation service falls primarily on the poor and marginalized community (Beyene et al., 2015). Badly served by the formal sector, the poor make their own often 
inadequate arrangements to meet basic survival needs any fetch water from a long distance or end up paying high prices to water renders for very small quantity of water (UN HABITAT, 2011).

Water supply, sanitation and hygiene situation in Ethiopia is very poor, as most of the population does not have access to safe and adequate water supply, sanitation and hygiene facilities as like most of developing country (GLAAS, 2010). As a result three-fourth of the health problems in Ethiopia is due to communicable diseases attributable to unsafe or inadequate watersupply and improper waste management particularly excreta (Abera et al., 2016). Diarrhoeal diseases caused by improper management of water and sanitation are among the major causes of infant and child morbidity and mortality (WHO/UNICEF, 2015). The combination of safe water supply, sanitation facilities and hygienic practices demonstrated a high potential in contributing to a remarkable decrease in the prevalence of a child and maternal morbidity and mortality (MoWR/EARO/IWMI/ILRI, 2002).

The estimated water service level of Ethiopia in terms of coverage, quantity, quality, and reliability is among the lowest in the world. Sanitation facilities are also in worst condition (FMOH, 2017). Due to unreliability of safe and unaccessbility of safe and sufficient water supply and adequate sanitation facilities the estimated service level could be in much less situation. These combine effect of the poor water supply and sanitation facilities in the country have high impact on the economic development of the country and the living condition of the towns' communities (Health, 2006).

As a result the existing health problem in the country is infectious disease is directly or indirectly caused by poor access to safe water supply and sanitation(Central Statistical Agency (CSA) [Ethiopia] and ICF. $2016,2016)$. The per capita of drinking water can not satisfy $50 \%$ of the minimum requirements. So, this condition exposed the people to prevent water borne diseases that accounts more than $40 \%$ of the communicable disease prevent in the country (MOWR, 2016). The aim of this study is to assess the knowledge,attitude and practice of water supply, sanitation and hygiene(WASH) in household on safe excreta disposal and the water storage container time.

\section{Methods}

\subsection{Study Area And Period}

The study was conducted at Arsi Nagele town. Arsi Nagele is a town in Southeastern Ethiopia located in the Western Arsi zone in the Oromiaregion on the paved highway north of Shashamane, this town has latitude and longitudeof $7^{0} 17^{\prime} 54^{\prime} \mathrm{N}$ to $7023^{\prime} 28^{\prime \prime} \mathrm{N}$ Latitude and38042" E Longitude with on elevation of 2043 meters above sea level (CSA, 2017). It is $225 \mathrm{~km}$ far from Addis Ababa in nourth of Hawassa and far from Shashemene about $25 \mathrm{~km}$. The total population of town is 136,086 from these male $66,562(48.9 \%)$ and female $69,522(51.1)$.Number of households in the town is 28,351 . The study was conducted from April 2011 E.C.

Study Design: A community based cross sectional study was conducted. 
Sample size determination and sampling techniques: The sample size for households were determined using Epi info version 7.1, by considering 99\% confidence level and marginal error (5\%). The sample size of households were calculated using P $=78 \%$ of the study conducted in Northwest Gojam (Beyene et al., 2015). The total sample size was 263 and taking $10 \%$ non-response rate the total sample size was 289 . Sample households were selected by systematic random sampling method. To ensure homogeneity, a random number was determined to select households by dividing the total number of household by the sample size.

Data collection instruments: The structured questionnaire was used to collect data through face to face interview by translating English questionnaire to Amharic language and backtranslated to English to ensure consistency and the knowledge, attitude and practices of each respondent in relation to water supply, sanitation, hygiene and its management was asked and supported by observational checklist .

Data quality control: To know the characteristic of questionnaire acceptance and willingness of respondents a pretest was carried one week before the actual data collection outside of the study area.

Data processing and analysis: Data was analyzed by using SPSS version 20 statistical software package and at the end the result was interpreted and discussed in line with study objectives so conclusion and recommendation was made based on study findings.

Ethical consideration: A formal letter was taken from Hawassa University, College of Medicine and Health Sciences, Institutional Research Review Board. Moreover, prior to contact with the households the purpose of study was discussed with Arsi Nagele town kebeles leaders and the permission for data collection was taken. Each respondent was clearly explained that participation is voluntary and they can decline at any time without any explanation if they wish to do so.

\section{Results}

\subsection{Socio- Demographic Data}

The minimum and maximum age of the respondent was 18 and 60 years respectively. The majority,(79\%) were in the age group of 18-35 (Table 1).

Table 1: Socio- demographic data of study subject, Arsi Nagele town, South eastern Ethiopia, April 2019. 


\begin{tabular}{llll}
\hline Variables & & Frequency & Percentage (\%) \\
\hline Age & $18-35$ & 229 & 79.2 \\
& $>35$ & 60 & 20.8 \\
Sex & Total & $\mathbf{2 8 9}$ & 100 \\
& Female & 129 & 43.6 \\
& Male & 160 & 56.4 \\
Religion & Total & $\mathbf{2 8 9}$ & 100 \\
& Orthodox & 82 & 28.37 \\
& Muslim & 165 & 57.04 \\
& Protestant & 35 & 12.1 \\
& Other & 7 & 2.42 \\
& Total & $\mathbf{2 8 9}$ & 100 \\
& Married & 180 & 62.28 \\
& Single & 91 & 31.42 \\
& Divorced & 13 & 4.6 \\
& Widowed & 5 & 1.7 \\
& Total & $\mathbf{2 8 9}$ & $\mathbf{1 0 0}$ \\
Occupatiol status & 20 & 6.92 \\
& Unable to read & 269 & 93.08 \\
& Literate & $\mathbf{2 8 9}$ & $\mathbf{1 0 0}$ \\
& Total & 65 & 22.5 \\
& Government employee & 84 & 29.06 \\
& Merchant & 20 & 7 \\
& Daily labor & 6 & 2.0 \\
& Farmer & 74 & 25.6 \\
& House wife & 40 & 13.84 \\
& Other & $\mathbf{2 8 9}$ & $\mathbf{1 0 0}$ \\
\hline & Total & &
\end{tabular}

3.2. Residents knowledge, attitude and practice towards water supply, sanitation and hygiene

3.2.1 Residents knowledge on water supply, sanitation and hygiene

Table 2: People'slevel of knowledge on WASH at Arsi Nagele town, South eastern Ethiopia, April 2019.

\begin{tabular}{lll}
\hline Knowledge score & Frequency & Percent \\
$1-8$ & 39 & 13.3 \\
$9-16$ & 88 & 30.5 \\
$17-24$ & 162 & 56.2 \\
Total & $\mathbf{2 8 9}$ & $\mathbf{1 0 0 \%}$ \\
\hline
\end{tabular}


Majority of the respondent $162(56.2 \%)$ were highly knowledgeable about water supply, sanitation and hygiene, others 88 (30.5\%) were moderately knowledgeable and 39(13.3\%) were non knowledgeable about things that matter for health (Table 2).

The greater part of the residents 126 (43.8\%) know private taps are safe for drinking and domestic use while $116(40.4 \%)$ of the respondents provided shared taps are safe. Additionally 31(10.5\%) know hand pump are safe and $16(5.3 \%)$ know unprotected well are safe for any purpose. The majority of residents $162(56.2 \%)$ indicated they experienced draw water from container by pouring, other $127(43.8 \%)$ know dropping from container. In the case of possibility contamination of water at home, about $113(39.1 \%)$ of the respondents had knowledge with regard to the poor personal hygiene where as $96(33.2 \%)$ of the respondents knowledge with regard to inappropriate cover other respondents $80(27.7 \%)$ knowledge with regard to poor clean lines of container (Table 3 ).

Table 3: Knowledge responses on water suppl in Arsi Nagele town, Southeastern Ethiopia, April 2019.

\begin{tabular}{llll}
\hline Knowledge test & Response & Frequency & $\mathbf{\%}$ \\
Pipe water safe for drinking & Yes & 283 & 97.93 \\
& No & 6 & 2.07 \\
Distance of source water from home in meter & Total & $\mathbf{2 8 9}$ & $\mathbf{1 0 0}$ \\
& $<10 \mathrm{~m}$ & 95 & 33 \\
& $11-100 \mathrm{~m}$ & 37 & 12.6 \\
& $101-200$ & 89 & 31 \\
Safe water is essential for health & $201-300$ & 68 & 23.4 \\
& Total & $\mathbf{2 8 9}$ & $\mathbf{1 0 0}$ \\
& Yes & 273 & 94.7 \\
& No & 16 & 5.3 \\
& Total & $\mathbf{2 8 9}$ & $\mathbf{1 0 0}$ \\
\hline
\end{tabular}

High number of respondents 229 (79.6\%) were knowledgeable on the matter that "sanitation is agroupof method to collect human excreta, urine and community waste in a hygienic way" where as $60(20.4 \%)$ of the respondents had wrong response on the issue. In the case of "environmental sanitation is the control of environmental factors that form links in disease transmission", 249(87.4\%) of the respondents gave correct response where as $36(12.6 \%)$ of the respondents gave wrong response to the issue (Fig.1).

The highest number of respondents $253(88.1 \%)$ provide positive response while $36(11.9 \%)$ of the respondents had negative response on the environmental sanitation is keeping our environment clean. The majority of the residents 264 (91.9\%) were knowledgeable on the matter that dirty place or home attracting flies"where as $25(8.1 \%)$ of the respondents had wrong response on the issue (Table 4). 
Table 4: Knowledge test on sanitation in Arsi Nagele town, South eastern Ethiopia, April 2019.

\begin{tabular}{|c|c|c|c|}
\hline Knowledge test & Response & Frequency & $\begin{array}{l}\text { Percentage } \\
\text { (\%) }\end{array}$ \\
\hline \multirow{4}{*}{ safe excreta disposal system } & use of latrine & 274 & 95.4 \\
\hline & Open defecation & 4 & 1.1 \\
\hline & Defecation under bush & 11 & 3.5 \\
\hline & Total & 289 & $100 \%$ \\
\hline \multirow[t]{4}{*}{ Reason of using latrine } & Privacy & 108 & 37.4 \\
\hline & To control disease & 86 & 30 \\
\hline & To avoid odour & 95 & 32.6 \\
\hline & Total & 289 & $100 \%$ \\
\hline \multirow{4}{*}{$\begin{array}{l}\text { Reason of not having solid waste } \\
\text { disposal }\end{array}$} & No ample space & 219 & 76.5 \\
\hline & $\begin{array}{l}\text { Fear of children and } \\
\text { animal fall }\end{array}$ & 52 & 18 \\
\hline & Not relevant to use & 18 & 5.5 \\
\hline & Total & 289 & $100 \%$ \\
\hline
\end{tabular}

The result showed that the majority of the residents 123 (42.5\%) knew about hand hygiene, 76 (26.4\%) was knowledgeable about food hygiene and 90 (31.1\%) was understand about safe disposal of faeces. The majority of the respondents know about the need of hygiene clean 132(35.9\%), 127(34.5\%) healthy and 109 (29.6\%) good for the need of hygiene (Fig.2).

The ways of maintaining the hygiene of respondent were hand washing with soap 107(37.02\%), bathing $92(31.3 \%)$ and clean the environment 90 (31.1\%). The importance of hand wash with soap were $101(34.9 \%)$ for prevention of disease, $132(45.5 \%)$ for deterrence of diarrheal and $56(19.3 \%)$ was for removal of germs. Among the respondents the ways acquiring diarrheal disease were lack of hand washing $140(48.4 \%)$, lack of cooking food 53(18.3\%) and was lack of treated water $96(33.2 \%)$. Lack of hygiene in their surrounding was differentiated were bad smell $136(47.05 \%)$, open defecation $83(28.7 \%)$ and faeces $70(24.2 \%)$. Most of the respondents ways of diarrheal disease prevention 125(43.2\%) were drinking clean water, $63(21.8 \%)$ dispose of children faeces in toilet facilities and 101(35\%) were hand washing with soap.

\subsubsection{Residents attitude on water supply, sanitation and hygiene}

There were only 133 (46.6\%) of the respondents who had unfavourable attitude to the issue that"the underlying cause of urban environmental sanitation problem is poverty" where as $2.5 \%$ and $50.9 \%$ of the respondents respectively had neutral and favourable attitude towards the view.About $43.8 \%$ of the 
respondents had favourable attitude while $29.3 \%$ and $26.9 \%$ of the respondents respectively had neutral (Table 5).

Table 5: Attitude responses on water supply in Arsi Nagele town, South eastern Ethiopia, April 2019.

\begin{tabular}{|c|c|c|c|}
\hline Attitude test & Response & Frequency & $\begin{array}{l}\text { Percentage } \\
(\%)\end{array}$ \\
\hline \multirow{4}{*}{$\begin{array}{l}\text { Water from any source safe for drinking and } \\
\text { domestic use }\end{array}$} & Agree & 82 & 28.4 \\
\hline & Disagree & 202 & 70.2 \\
\hline & No idea & 5 & 1.4 \\
\hline & Total & 289 & $100 \%$ \\
\hline \multirow{4}{*}{$\begin{array}{l}\text { Water free from visible particle safe for } \\
\text { drinking }\end{array}$} & Agree & 211 & 73.3 \\
\hline & Disagree & 24 & 8.1 \\
\hline & No idea & 54 & 18.6 \\
\hline & Total & 289 & $100 \%$ \\
\hline \multirow[t]{4}{*}{ Dirty water can transmit disease } & Agree & 233 & 81.1 \\
\hline & Disagree & 6 & 1.7 \\
\hline & No idea & 50 & 17.2 \\
\hline & Total & 289 & $100 \%$ \\
\hline \multirow[t]{4}{*}{ hand washing before dipping is safe } & Agree & 202 & 70.2 \\
\hline & Disagree & 40 & 13.7 \\
\hline & No idea & 47 & 16.1 \\
\hline & Total & 289 & $100 \%$ \\
\hline \multirow[t]{4}{*}{ pipe borne water always safe } & Agree & 183 & 63.5 \\
\hline & Disagree & 98 & 34.1 \\
\hline & No idea & 8 & 2.4 \\
\hline & Total & 289 & $100 \%$ \\
\hline \multirow[t]{4}{*}{ treated water are prevent from disease } & Agree & 130 & 44.9 \\
\hline & Disagree & 112 & 38.9 \\
\hline & No idea & 47 & 16.2 \\
\hline & Total & 289 & $100 \%$ \\
\hline
\end{tabular}

There were only $133(46.6 \%)$ of the respondents who had unfavourable attitude to the issue that "the underlying cause of urban environmental sanitation problem is poverty" where as $2.5 \%$ and $50.9 \%$ of the respondents respectively had neutral and favourable attitude towards the view.About $43.8 \%$ of the respondents had favourable attitude while $29.3 \%$ and $26.9 \%$ of the respondents respectively had neutral and unfavourable attitude to the view that "the impact of inappropriate dumping wastes in open fields 
and around road sides causes the area loses its natural beauty,badodour to the community, health problems on the society and pollution of surface and groundwater".

About fifty nine percent $(58.7 \%)$ of the respondents had unfavourable attitude, they were against the idea that "open burning of wastes has no impact on the health of human being." Whereas $39.6 \%$ of the respondents had favourable attitude and $1.7 \%$ of the respondents had neutral attitude on the case.

Majority of the respondent had positive attitude $258(90.5 \%)$ while $20(7.1 \%)$ of the respondents negative and $7(2.5 \%)$ neutral attitude to the issue that in proper disposal of solid and liquid waste may contribute to the transmission of disease. Moreover, 239 (83.9\%) of the respondent had positive attitude while $31(10.8 \%)$ and $15(5.2 \%)$ of the respondents had negative and neutral attitude to the view that human waste disposal is not a problem in that area. As the result showed that 56(19.6\%) positive attitude while $217(76.2 \%)$ and $12(4.2 \%)$ of the respondents had negative and neutral attitude regarding to children faeces were not dangerous as adult.

Table 6: Attitude responses on sanitation in Arsi Nagele town, South Eastern Ethiopia, April 2019.

\begin{tabular}{|c|c|c|c|}
\hline Attitude test & Response & Frequency & $\begin{array}{l}\text { Percentage } \\
(\%)\end{array}$ \\
\hline \multirow{3}{*}{$\begin{array}{l}\text { Waste disposal method is a problem in your } \\
\text { neighbourhood }\end{array}$} & Agree & 229 & 79.6 \\
\hline & Disagree & 60 & 20.4 \\
\hline & Total & 289 & $100 \%$ \\
\hline \multirow{3}{*}{$\begin{array}{l}\text { Hand washing facility connected to the latrine } \\
\text { is safe for health }\end{array}$} & Agree & 273 & 95.1 \\
\hline & Disagree & 16 & 4.9 \\
\hline & Total & 289 & $100 \%$ \\
\hline \multirow[t]{3}{*}{ Diarrhoeaillnessis related to hygienepractices? } & Agree & 246 & 85.6 \\
\hline & Disagree & 43 & 14.4 \\
\hline & Total & 289 & $100 \%$ \\
\hline \multirow[t]{3}{*}{ Income is facilitating poor sanitation } & Agree & 231 & 80.4 \\
\hline & Disagree & 58 & 19.6 \\
\hline & Total & 289 & $100 \%$ \\
\hline \multirow{4}{*}{$\begin{array}{l}\text { Using the same latrine with other family } \\
\text { members are comfortable }\end{array}$} & Agree & 87 & 30.2 \\
\hline & Disagree & 192 & 66.6 \\
\hline & No idea & 10 & 3.2 \\
\hline & Total & 289 & $100 \%$ \\
\hline
\end{tabular}


The majority of respondents 267 (93.7\% ) believed that hand washing with soap was good and 18(6.3\%) were negative attitude to the idea. However, $273(95.8 \%)$ of the respondent had positive attitude and $12(4.2 \%)$ negative attitude regarding to poor personal hygienic was cause of diarrheal in the same manner $269(94.4 \%)$ and $16(5.6 \%)$ of the respondents had positive and negative attitude in the case of good hygiene was preventing from disease (Table 6).

The result showed that the highest percentage of respondents had positive attitude $280(98.2 \%)$ and $9(1.8 \%)$ of respondents had negative attitude to the view that not hand washing before meal has health effect. The type of water used while washing your body $199(69.1 \%), 28(9.5 \%)$ and $61(21.4 \%)$ of the respondent had using pipe water, spring and well water respectively.The majority of respondents 261 (90.9\%) believed that trimming finger nail was good for health and $28(9.1 \%)$ were negative attitude to the idea.

\subsubsection{Residents practice on water supply, sanitation and hygiene}

The majority of respondent $250(87.1 \%)$ had good practice in case of cover the water storage container during the time of visit while $39(12.9 \%)$ of the respondent had bad practice.results indicated that most (46.6\%) of the respondents treat their drinking water by boiling, while about $33.7 \%$ use water filters, $7.8 \%$ use sedimentation and the rest $11.9 \%$ was no measurement taken. Most residents $196(68.1 \%)$ had good practice in case of a separate drinking can while 93(31.9\%) was not in practice (Table 7).

Table 7: Family size and household water consumption in liter/day in Arsi Nagele town, South Eastern Ethiopia, April 2019.

\begin{tabular}{|c|c|c|c|c|c|c|c|}
\hline \multirow[t]{2}{*}{ Family size } & \multicolumn{5}{|c|}{ Per household water consumption in liter } & \multirow{2}{*}{ Total } & \multirow[t]{2}{*}{$\%$} \\
\hline & $<50$ & $51-90$ & $91-130$ & $131-170$ & $>170$ & & \\
\hline $1-3$ & 15 & 22 & 24 & 8 & 0 & 69 & 23.5 \\
\hline $4-6$ & 22 & 42 & 15 & 14 & 0 & 93 & 32 \\
\hline$>7$ & 12 & 66 & 43 & 4 & 2 & 127 & 44.5 \\
\hline Total & 49 & 130 & 82 & 26 & 2 & 289 & 100 \\
\hline$\%$ & $16.8 \%$ & $45.3 \%$ & $28.4 \%$ & $8.8 \%$ & $0.7 \%$ & $100 \%$ & $100 \%$ \\
\hline
\end{tabular}

About $285(94.4 \%)$ of respondent clean and kept in clean place while 14(5.6\%) bad practice in this case, additionally $239(83.2 \%)$ of the respondents were cleaned collection material regularly where as $50(16.8 \%)$ was not practice. Most of the respondent 129(44.9\%) wash the storage containers used for drinking water monthly, 104(36.1\%) weekly, 52(18\%) daily and 4(1\%) had bad practice.

Around $43.5 \%$ of the respondents dumped their household waste in an open space, $31.2 \%$ of the respondents in the field and $25.3 \%$ at garbage collection and also $249(87.4 \%)$ of respondent dispose their liquid waste splash on the ground where as 36 (12.6\%) were sock into ground (Fig.3). 
Table 8: Practice responses on sanitation in Arsi Nagele town, South Eastern Ethiopia, April 2019.

\begin{tabular}{llll}
\hline Practice test & Response & Frequency & $\mathbf{\%}$ \\
Frequency of hand washing & once in a day & 13 & 4.6 \\
& always afterdoing something & 110 & 38.2 \\
& always beforedoing some thing & 163 & 56.5 \\
& Never & 3 & 0.7 \\
& Total & $\mathbf{2 8 9}$ & $\mathbf{1 0 0 \%}$ \\
Utilization of latrine & Properly & 245 & 85.3 \\
& Improperly & 37 & 12.6 \\
& Do not use at all & 7 & 2.1 \\
Kinds of solid waste disposal & Total & $\mathbf{2 8 9}$ & $100 \%$ \\
& Disposal in pit & 54 & 18.6 \\
& Animal feeding & 217 & 75.4 \\
& Total & 18 & 6 \\
\hline
\end{tabular}

Majority (98.9\%) of survey respondents affirmed that they have the habit of hand-washing, often with water and soap (64.9\%), 33.4\% water only and $1.7 \%$ water with ash. Most(70.5\%) of the respondents wash their bodyonce a week, $3.2 \%$ three times in a week while others do it twice $(25.3 \%)$ or day to day(1.1\%) (Table 8). About $93.3 \%$ of the respondents claimed that their children have the habit of washing their hands too,often with soap and water. The do this two (35.1\%) to three (47.7\%) times a day usually before eating. Only $28.4 \%$ of the respondents had fixed hand-washing place/station in their homes and the rest $71.6 \%$ had not practice (bad practice) (Fig.4).

\section{Discussion}

The majority of the respondents 126 (43.8\%) know private taps are safe for drinking and domestic use while $116(40.4 \%)$ shared taps are safe and also 31(10.5\%) know hand pump are safe and $16(5.3 \%)$ know unprotected well are safe for any purpose. This result is less than the study done in Sidama zone (Belachew, 2012) and study reports by (Belachew, 2012).

The majority of respondents in the study collect water in small covered containers such as jerrycans $46.3 \%$, buckets $34.5 \%$, barrels $16.4 \%$ and $2.8 \%$ of residents indicated that they collected water in clay pot. This finding is in line with the study reported by Telmo, (2002) majority of residents collect water in small covered containers such as jerrycans $45.5 \%$ and buckets (35.8\%). Moreover, $7.6 \%$ of residents indicated that they collected water in barrels but they did not specify whether these containers were covered after collection. It should also be noted observation that wide neck containers such as buckets have been 
associated with increased water contamination in comparison to small neck containers such as jerry cans. This is probably because with wide neck containers there is agreater tendency to insert water drawing devices (such as cups) and a larger surface area is exposed to contaminating agents when uncovered(Unicef, 2012).

High number of respondents $229(79.3 \%)$ were knowledgeable on the matter that"sanitation is agroupof method to collect human excreta, urine and community waste in a hygienic way." Where as $60(20.7 \%)$ of the respondents had wrong response on the issue which is less compared to the study reported by USAID (2010) which is about $289(83.2 \%)$. Almost all of the community understand about "sanitation is a group of method to collect human excreta, urine and community waste in a hygienic way" awerness of the community is changed by different means. Most of the community on the study area were aware of it this might be due to awareness creation by different means such as expansion of extension programmes mass media and which is countrary to the study report by FDRE ( 2017 )which is about $17.4 \%$. This difference probably due the study participats are urban residents in this study which is campaorable with WHO report (WHO, 2018). When you compare from the study area there were only $133(46.6 \%)$ of the respondents who had unfavourable attitude to the issue that "the underlying cause of urban environmental sanitation problem is poverty" where as $2.5 \%$ and $50.9 \%$ of the respondents respectively had neutral and favourable attitude towards the view community of the study area thinks environmental sanitation was done with co-operation of surrounding rather than economic different.

The main improved water source for most of the residents either use pipe borne water in their homes $(58 \%)$, public stand pipes $(27.8 \%)$, yard connections $(5.6 \%)$, or collect rain water $(0.6 \%)$. These are all regarded as improved water sources and collectively make up a total $92 \%$ of the water which residents use which is high compared with the study reported by Oxfam/Unicef, (2013).

Regarding to waste dumping $51.4 \%$ of the respondents had favourable attitude while $24.6 \%$ and $24 \%$ of the respondents respectively had neutral and unfavourable attitude to the view that "the impact of in appropriate dumping wastes in open fields and around road sides causes the area loses its natural beauty, bad odour to the community, health problems on the society and pollution of surface and groundwater" which is inline with the study report by Organization, (2010). When compared with the study area majority of the respondent had positive attitude 260 (90.5\%) while 21 (7.1\%) of the respondents negative and $8(2.5 \%)$ neutral attitude to the issue that in proper disposal of solid and liquid waste may contribute to the transmission of disease. Moreover, $241(83.9 \%)$ of the respondent had positive attitude while $32(10.8 \%)$ and $16(5.2 \%)$ of the respondents had negative and neutral attitude to the view that human waste disposal is not a problem in that area which less compared the study reported by (Corps, 2008). Arsi Nagele is known for its large church, dedicated to St. Gabriel which is the site of massive twice yearly pilgrimages (on 26 July and 28 December) attended by tens of thousands of orthodox pilgrims. So, a lot of people attended on this festivity whi'ch is probably the cause for high amount of solid and liquid waste which lead to loses its natural beauty, bad odour to the community, health problems on the society and pollution of surface and groundwater(Bandaragoda, 1997). 
In the study area $43.5 \%$ of the respondents dumped their household waste in an openspace, $31.2 \%$ of the respondents in the field and $25.3 \%$ at garbage collection and also $249(87.4 \%)$ of respondent dispose their liquid waste splash on the ground where as 36(12.6\%) were sock into ground. Biran et al.(2014) described that improved environmental sanitation management reduces environmental burdens, increases sustainability of environmental resources and allows for a healthier, more secure future for the population. All sanitation technologies are deemed adequate as long as they are private or shared of public and provided that the hygienic separation of human excreta from human contact exists. Public latrines fail to provide an adequate solution to the community excreta disposal needs because of problems with adequacies in their maintenance and in accessibility at night by the elderly, disabled and young children. It should be noted that these inadequacies sometimes lead to open defecation or inappropriate excreta disposal which sometimes reach sensitive aqueous environments or pose risks of human contact.

Generally, most of the residents have knowledge and attitude about water supply, sanitation and hygiene but they are not practice what they know. Sanitation improvement is gradual and it may take a long time to notice the impact this may be achieved through creating awareness on the bad impact of poor sanitation to the public health, cooperation among various stakeholders and take responsibility in introducing and implementing rules and laws that are related to environmental protection and sanitation by the government.

\section{Conclusion And Recommendation}

\subsection{Conclusion}

Based on this finding it has been evident that the majority of respondents were knowledgeable about water supply, sanitation and hygiene; however it was not adequate as water supply, sanitation and hygiene is one of the basic elements and human right of the health living of human being, and most of the residents were expected to acquire high level of knowledge. Where as asmajority of respondents were not practise what they have known.

Greater part of the respondents had favourable attitude to water supply, sanitation and hygiene but there was some in consistencies on residents attitude. These variations might be due to lack of knowledge and information, or existence of weak social norms in the value system of the community concerning WASH.

Majority of the residents of Arsi Nagele town did not take actions to improve environmental sanitation in their living area. This indicated that they were not as such sacrificing their personal interest for the sake of WASH. This lack of action might be the weakness of the communities and other stakeholders to do different practical activities in group in order to maintain urban environmental sanitation.

\subsection{Recommendations}

Based on the finding of the study the following recommendations were provided: 
- District health office take responsibility for health education and hygiene awareness should be promoted to influence the resident's attitude that target personal, household and community WASH.

- Special consideration should be given by city administration to integerate practical engagement of the residents in the community through developing sewerage system, urban beautification and toilet facility.

- This will help to create awareness as well as alter the negative attitude and practice related to WASH.

- Extension workers should undertake continuous home visit to improve the sanitation of the compound and home.

- Government should be motivated community to take part in different community activities; this will help them to have the exposure to value how their role is important and become committed for the improvement of WASH.

- The municipality must assign enough budgets to enlarge water services

- Good governance should be exercised to encourage water supply, sanitation and hygiene through the participation of different stakeholders (government, NGOs and communities) in decision making.

\section{Declarations}

\section{Acknowledgements}

We are very grateful College of Medicine and Health Sciences of Hawassa University, for supporting the research. We are thankful to Arsi Nagele city municipality and the population the town residents for cooperation.

\section{Availability of data and materials}

The raw data of this research can be made available upon request from the corresponding author.

\section{Ethics approval and consent to participate}

No human data was used and, therefore, ethical approval is not required.

\section{Consent for publication}

Not applicable.

\section{References}

[1] Abera, B. et al. (2016) 'Water safety, sanitation and hygiene related knowledge, attitudes and practices among household residents in peri- urban areas in Northwest Ethiopia', pp. 1-7.

[2] Bandaragoda, D. O. N. J. (1997) SOCIO-ECONOMIC BASELINE SURVEY FOR A PILOT PROJECT ON WATER USERS ORGANIZATIONS IN THE HAKRA 4-R DISTRIBUTARY COMMAND AREA, PUNJAB. 
[3]Belachew, M. (2012) ASSESSMENT OF DRINKING WATER QUALITY AND DETERMINANTS OF HOUSEHOLD POTABLE WATER CONSUMPTION IN SIMADA DISTRICT, ETHIOPIA.

[4] Beyene, A. et al. (2015) 'Situational Analysis of Access to Improved Sanitation in the Capital of Ethiopia and the Urgency of Adopting an Integrated Fecal Sludge Management ( FSM ) System', 3(5), pp. 726-732. doi: 10.11648/j.sjph.20150305.29.

[5] Biran, A. et al. (2014) 'Eff ect of a behaviour-change intervention on handwashing with soap in India ( SuperAmma ): a cluster-randomised trial', The Lancet Global Health. Biran et al. Open Access article distributed under the terms of CC BY, 2(3), pp. e145-e154. doi: 10.1016/S2214-109X(13)70160-8.

[6] Central Statistical Agency (CSA) [Ethiopia] and ICF. 2016 (2016) EDHS 2016. Addis Ababa, Ethiopia, and Rockville, Maryland, USA: CSA and ICF. Addis Ababa. Available at: https://dhsprogram.com/pubs/pdf/FR328/FR328.pdf.

[7] Corps, M. (2008) Baseline Survey Water, Sanitation and Hygiene Water, Sanitation and Hygiene. [8] CSA (2017) Federal Democratic Republic of Ethiopia Central Statistical Agency Population Projection of Ethiopia for All Regions At Wereda Level from 2014 - 2017.

[9] Dreibelbis, R. et al. (2013) 'The Integrated Behavioural Model for Water, Sanitation, and Hygiene: A systematic review of behavioural models and a framework for designing and evaluating behaviour change interventions in infrastructure-restricted settings', BMC Public Health. BMC Public Health, 13(1), p. 1. doi: 10.1186/1471-2458-13-1015.

[10] FDRE (2017) National School Water, Sanitation and Hygiene (SWASH) Implementation Guideline.

[11] FMOH (2017) Ethiopia Overview: Water, sanitation and hygiene.

[12] GLAAS (2010) The UN-Water GLAAS Strategy. Available at: http://www.who.int/water_sanitation_health/publications/glaas_strategy.pdf?ua=1.

[13] Health, F. D. R. of E. M. of (2006) Federal Democratic Republic of Ethiopia Ministry of Health National Hygiene and "On-Site" Sanitation Protocol.

[14] MoWR/EARO/IWMI/ILRI (2002) 'Integrated water and land management research and capacity building priorities for Ethiopia Integrated water and land management research and capacity building priorities for Ethiopia'.

[15] MOWR (2016) THE FEDERAL DEMOCRATIC REPUBLIC OF ETHIOPIA.

[16] Organization, L. A. W. T. (2010) WASH Marketing Project Kampong Speu Baseline Survey. Kampong Speu. 
[17] Oxfam/Unicef (2013) A 2013 study on current community access to and practices on Water, Sanitation and Hygiene in select rural and urban settlements in Liberia. Liberia.

[18] Telmo, A. C. (2002) A water supply and sanitation study of the village of Gouansolo in Mali, West Africa. MICHIGAN.

[19] UNHABITAT (2011) Knowledge, Attitudes and Practices Survey On WATER, SANITATION AND HYGIENE Wundwin Township.

[20] Unicef (2012) Water, Sanitation and Hygiene (WASH) in Schools, Unicef. Available at: https://www.unicef.org/publications/files/CFS_WASH_E_web.pdf.

[21] USAID (2010) USAID Hygiene Improvement Project for Amhara region: WASH friendly Schools.

[22] WHO/UNICEF-JMP (2017) Progress on Drinking Water, Sanitation and Hygiene, Drinking Water, Sanitation and Hygiene. Available at: http://apps.who.int/bookorders.

[23] WHO/UNICEF (2015) Water, sanitation and hygiene in health care facilities - urgent needs and actions, Global Meeting.

[24] WHO (2018) Strengthening the quality and sustainability of water, sanitation and hygiene services, including in health care facilities. WHO-DFAT project inception meeting 27-29 September 2018 Bali, Indonesia Meeting report. 